\title{
Conditional discrimination in the squirrel monkey'
}

E. M. BARGE, JR. ${ }^{2}$ and ROGER $K$. THOMAS, University of Georgia, Athens, Ga. 30601

Four squirrel monkeys were trained to 90\% criterion on a simple discrimination problem, a two-object conditional discrimination problem, and a one-odd conditional discrimination problem. Significant interproblem improvement was seen on the one-odd task. Detailed analyses of the data suggested that parts of the conditional discrimination problems were learned separately rather than some overall concept of the reward contingencies.

Conditional discrimination, as the term has been used in the nonhuman primate literature, has been described by French (1965, p. 174) as follows:

"In the simplest of conditional discriminations, there are two separable sets of discriminanda: one simultaneous and one successive. All members of the simultaneous set are present on all trials. Only one member of the successive set appears on any trial. It signals the positive and negative members of the simultaneous set for that trial."

There are several forms of conditional discrimination problems, and on one form or another, rats (Lashley, 1938; North, Maller, \& Hughes, 1958), cats (Joshi \& Warren, 1963), rhesus monkeys (Noer \& Harlow, 1946), chimpanzees (Nissen, Blum, \& Blum, 1949) and children (Gollin \& Liss, 1962) have been reported to master this type of learning problem.

Apparently the squirrel monkey has not been tested with problems that are compatible with French's (1965) description of conditional discrimination. However, Woodburne \& Rieke (1966) reported data on what they identified as a "Symbolic problem-one block" that appears to be similar to conditional discrimination. They presented the monkey with one of eight different sets of lines (e.g., 5 horizontal lines, 5 vertical lines, 20 vertical lines, etc.) as a sample which was then withdrawn, and the monkey was allowed to respond to one of three geometric forms. Correct responding depended on which geometric form was associated with the previously shown pattern of lines. The problem differs from the traditional conditional discrimination problem in that the successive discriminandum was not present with the simultaneous discriminandum.

The present work studied the squirrel monkey's ability to learn and perform a two-object conditional discrimination problem and a one-odd conditional discrimination problem.

\section{METHOD AND PROCEDURE}

The Ss were four naive, adult male squirrel monkeys (Saimiri sciureus). One month prior to training, the Ss were individually caged, and a standard feeding routine of five to six Purina Monkey Chow biscuits was established (this was sufficient to maintain body weight; in addition fresh fruit was given twice per week). During the experiment, the Ss were fed following the daily training session.

The Ss were trained in a gray, modified WGTA. The successive discriminanda in both problems were a black or white stimulus tray. The simultaneous discriminanda in the simple conditional discrimination problem were a cross and a parallelo. gram (constructed of balsa wood, approximately $1 \times 2 \times 3$ in. and painted gray). The simultaneous discriminanda in the one-odd problem were circles and an I-shaped object (same construction as the first problem; the circles had a 2 -in. diam and were 1 in. high).

General procedures for all problems were (a) reinforcement with currants, (b) intertrial intervals of $30 \mathrm{sec}$, and (c) limit of 40 trials per day. Training was conducted in a small air-conditioned room which was illuminated only by a $25-\mathrm{W}$ bulb mounted in the top center of the WGTA. The air conditioner provided an effective masking noise and a constant temperature of $75 \mathrm{deg} F$.

Three procedures were used to shape the Ss. (a) First, the Ss responded with reinforcement 25 times to one of two uncovered foodwells; the rewarded foodwell on a given trial was randomly determined. (b) Second, the Ss learned to displace a gray cube which was randomly positioned over one of two foodwells; this was done until 25 reinforcements were obtained. (c) Finally, the Ss were trained on a simple objectdiscrimination problem (gray triangle vs gray circle with the triangle always reinforced and the positions of the objects randomly determined) until 36 of 40 successive trials $(90 \%)$ were responded to correctly.

The simple conditional discrimination problem was structured such that if the stimulus tray was black, the cross was reinforced, but if the tray was white, the parallelogram was reinforced. The positions of the cross and parallelogram and the sequences of stimulus-tray presentations
Table 1

Mean Trials to Criterion and Errors in the Shaping and Discrimination Tasks

\begin{tabular}{ccc}
\hline \multicolumn{1}{c}{ Task } & Trials to Criterion & Errors \\
Shaping 1 & 25.5 & 1.0 \\
Shaping 2 & 27.0 & 2.0 \\
Simple discrimination & 61.8 & 9.8 \\
Conditional discrimination & \\
two-object & 420.0 & 141.8 \\
one-odd & 183.3 & 49.5 \\
\hline
\end{tabular}

were randomly determined. Training was continued until a criterion of 36 correct of 40 successive trials was seen.

The one-odd conditional discrimination was arranged so that on a given trial, two gray circles and one gray I-shaped object were present. If the stimulus tray was black, reinforcement was under the I form, but if the tray was white, either circle was reinforced. Object positions and tray brightness sequences were randomly determined. Training was continued to a criterion of 36 correct of 40 successive trials. RESULTS

All Ss reached criterion in all tasks. The mean number of trials to criterion and errors for each of the shaping and training tasks may be seen in Table 1 . Individual $S$ performances in the two-object conditional discrimination task ranged from 280 to 560 trials to criterion; whereas, on error scores the range was from 104 to 190 . The range of individual performances on the one-odd conditional discrimination problem was 80 to 240 trials to criterion and 17 to 74 errors. Significantly fewer trials to criterion (Mann-Whitney $U, p=0.014$ ) and significantly fewer errors (Mann-Whitney $U$, $p=0.014$ ) were seen in the one-odd conditional discrimination problem than were seen on the two-object conditional discrimination problem.

Chi-square analyses of the differences in error scores when the reinforced object was on the left vs the right in the two-object conditional discrimination problem indicated that position was a significant factor for three Ss. Two Ss had significantly more errors when the reinforced object was on the right $(\mathrm{p}<0.001)$, while one $S$ had significantly more errors on the left $(p<0.01)$. Similar analyses for the one-odd problem indicated that one $S$ made significantly more errors when the reinforced object was in the center position $(\mathrm{p}<0.025)$.

Chi-square analyses of the differences in error scores on the two-object conditional discrimination problem as a function of the brightness of the stimulus tray indicated that significantly more errors were committed by three $S s$ if the tray was black $(p<0.005)$. Similar analyses for the one-odd problem suggested that tray brightness was a factor for two Ss 
( $p<0.001$ ); however, one S had more errors with the white tray and the other had more errors with the black.

\section{DISCUSSION}

The results show that the squirrel monkey is capable of learning two classical variations of conditional discrimination. The significant interproblem improvement in performance from the two-object to the one-odd conditional discrimination problem suggests that the Ss may have been forming a set to learn (this was corroborated by post hoc training with the same Ss soon after completion of the present experiments on five different two-object conditional discrimination problems; the Ss learned these problems with means of $169,100.5,104.2$, 138.2 , and 189.5 trials to the same criterion as previous problems and $58.2,29,23.5$, 34.8 , and 57.2 mean errors); however, it is possible that the one-odd problem was inherently easier to learn than the twoobject problem.

The analyses of errors as a function of tray brightness suggested that this was a significant factor for some of the monkeys. These findings suggest that the monkeys may have learned parts of the conditional discrimination separately rather than learning the overall concept of the reward contingencies. For example, the data suggest that the white-tray/parallelogram association was learned with significantly fewer errors than the black-tray/cross association.

\section{REFERENCES}

FRENCH, G. M. Associative problems. In A. M. Schrier, H. F. Harlow, and F. Stollnitz (Eds.) Behavior of non-human primates Vol. 1. New York: Academic Press, 1965.

GOLLIN, E. S., \& LISS, P. Conditional discrimination in children. Journal of Comparative \& Physiological Psychology, 1962, 55, 850-855.

JOSHI, B. L., \& WARREN, J. M. Discrimination of ambivalent cue stimuli by cats. Journal of Psy chology, 1955, 47, 3 .

LASHLEY, K. S. Conditional reactions in the rat Journal of Psy chology, 1938, 6, 311-324.

NISSEN, H. W., BLUM, J. S., \& BLUM, R. A. Conditional matching behavior in chimpanzee: Implications for the study of comparative study of intelligence. Journal of Comparative \& Physiological Psychology, 1949, 42, 339-356.

NOER, M. C., \& HARLOW, H. F. Discrimination of ambivalent cue stimuli by macaque monkeys. Journal of General Psychology, 1946, 34, 165-177.

NORTH, A. J., MALLER, O., \& HUGHES, C. Conditional discrimination and stimulus patterning. Joumal of Comparative \& Physiological Psychology, 1958, 51, 711-715.

WOODBURNE, L. S., \& RIEKE, C. K. Response to symbols by squirrel monkeys. Psychonomic Science, $1966,5,429-430$.

$$
\text { NOTES }
$$

1. The present work was based on the MS thesis of the first author at the University of Georgia.

2. Now serving in the U.S. Army. Address reprint requests to the second author.

\section{Alcohol ingestion without oropharyngeal sensations}

\section{ZALMAN AMIT and MURIEL H. STERN, McGill University, Montreal, Canada}

Rats pressed a lever significantly more often in the condition of simultaneous presentation of water orally and alcohol by direct infusion to the stomach than in the reverse condition With no oral presentation, Ss pressed significantly oftener for alcohol infusion than for water infusion, suggesting the development of an alcohol preference.

The laboratory rat's well-known reluctance to drink alcohol in high concentrations is usually attributed by research workers to the aversive properties of the taste and smell of alcohol. The evidence for this is inferential, and does not appear to have been demonstrated directly.

The present study was designed to explore the relation between taste and voluntary alcohol ingestion in the rat, by eliminating the oropharyngeal sensations associated with ingestion of alcohol by mouth, while maintaining the voluntary aspects of ingestion. Our objectives were to determine: (a) whether the absence of taste and smell would eliminate the aversion to alcohol and create a preference for it, and (b) if experience with alcohol under such conditions would change subsequent behavior in a free-choice water-alcohol situation.

\section{SUBJECTS}

Subjects were 18 male hooded rats, weighing between $250-275 \mathrm{~g}$ and approximately 100 days old at the beginning of the experiment. All Ss were implanted with an intragastric fistula, following a modification of the method described by Kohn (1951). The tube was brought to the outside of the animal, on top of the head, where it was attached to a syringe needle that was cut $1 / 4$ in. below the female taper and bent to a 90-deg angle. The syringe was then cemented to the skull. Four days after operation, at the beginning of the pretraining period, the Ss were placed on a 22 -h water-deprivation schedule.

\section{APPARATUS}

The apparatus was a single-lever Skinner box, with a liquid dispenser, which delivered $.05 \mathrm{ml}$ of liquid per lever press. The lever also operated a multispeed infusion pump (Multispeed-Transmission, Harvard Co., Dover, Mass.) that was attached to the female taper of the intragastric fistula and was also calibrated

\section{to deliver $.05 \mathrm{ml}$ of liquid.} PROCEDURE

Fourteen of the animals were pretrained to press the lever for water on a continuous reinforcement schedule. The acquisition criterion was 50 lever presses in a 10-min period, on three consecutive daily sessions. The experimental conditions were imposed on the day following criterion performance, and obtained for the following 14 days. Daily experimental sessions were of 12-min duration. During the experimental sessions, the initial lever depression was followed immediately by the presentation of liquid in the dispenser and a simultaneous injection through the infusion pump directly into the stomach. The liquid dispenser then became inoperative, for $3 \mathrm{sec}$, during which time a lever depression resulted only in the operation of the infusion pump and the delivery of fluid into the stomach. One group of animals $(\mathrm{N}=7)$ received $17 \%$ alcohol $(\mathrm{vv})$ in the liquid dispenser and water infused to the stomach, and a second group $(\mathrm{N}=7)$ received water in the liquid dispenser (that is, by mouth) and the $17 \%$ alcohol directly to the stomach. It follows, then, that during the 3-sec period in which the liquid dispenser was inoperative, none of the animals could drink either liquid but seven of them could receive water and seven of them could receive alcohol, infused directly into the stomach. The remaining four animals were not placed in the experimental situation but for the 14 days of the experimental period were given a choice between water and $17 \%$ alcohol for $2 \mathrm{~h}$ per day in their home cages. Following the 14-day experimental period, all 18 animals were maintained on 22 -h water deprivation for 7 days, during which time they were given a free choice of water or $17 \%$ alcohol for a daily $2-h$ period.

\section{RESULTS}

During the 14-day experimental period, Ss that received alcohol by infusion and water by mouth ingested more alcohol than did the Ss that received water by infusion and alcohol by mouth. An analysis of variance revealed that this difference was significant at the .001 level of probability. The difference was reflected in the two measures of rate of lever pressing the study generated: (a) When the liquid dispenser was operating, Ss that received alcohol by infusion and water by mouth pressed the lever at a rate consistently higher than than of the Ss that received 